\title{
New Modification of Koyanagi Technique Using Dartos Muscle Flap in Management of Proximal Hypospadias
}

\author{
Tarek Abd El Hamed Keshk, Yasser Mohamed Omar El Sheikh, Mahmoud Abd El Rahman, Haytham \\ Shaker Ahmed Rezq, Hanan Ali Ali Dawod \\ Plastic Surgery Department, Faculty of Medicine, Menoufia University, Menoufia, Egypt \\ *Corresponding Author: Haytham Shaker Ahmed Rezq, Mobile: +965 60039355 , \\ E-mail: drhaythamshaker@yahoo.com
}

\begin{abstract}
Background: One stage urethroplasty through parameatal foreskin flap (OUPF) available for all types of hypospadias was first described by Tomohiko Koyanagi (1983). High complication rates were reported.

Objective: To evaluate the outcome of Koyanagi technique modification using dartos muscle as a $2^{\text {nd }}$ layer because it has a high vascularity, very thin, easily elevated, and leaves no complications.

Patient and methods: This study was conducted in the Plastic Surgery Department at Menoufia University, during the period of April 2017 to April 2019. Thirty cases for proximal hypospadias were included during this study. After chordee release, urethra was constructed using Koyanagi technique and adding scrotal dartos muscle flap as a $2^{\text {nd }}$ layer. Results: Patient's age ranged from 1 to 4 years with mean age of $2.83 \pm 1.17$. All of the 30 cases were with proximal hypospadias and had severe chordee. Early complications were detected as bleeding in 2 patients $(6.6 \%)$. One patient (3.3\%) reported for retention due to obstruction of the inserted catheter. Another case (3.3\%) showed wound infection. The reported late complications were fistula in 6 patients $(20 \%)$, meatal recession in 5 patients $(16.6 \%)$, meatal stenosis in 3 patients (10\%), and diverticulum in one patient (3.3\%).

Conclusion: The modified Koyanagi one stage repair of proximal hypospadias is an innovative technique and realize many criteria for expected effective operating results. The use of dartos muscle flap as a cover for the urethroplasty improves the results and minimize complications.
\end{abstract}

Keywords: Dartos muscle flap, Management, Modification of Koyanagi, Proximal hypospadias.

\section{INTRODUCTION}

Hypospadias is one of the commonest congenital anomalies, through the incidence about 1 in 300 live births. Proximal hypospadias may be mi penile (20$30 \%$ of cases), or posterior penile, penoscrotal, scrotal, or perineal (10-15\% of cases) all of them have chordee ${ }^{(1,2)}$. Proximal hypospadias shows the most challenging and complex manifestations and might be treated successfully using one of several one- or multiple-stage techniques ${ }^{(3)}$. All evolved different surgical techniques of repair target the same purpose, to give the child a straight penis with a terminal meatus with least morbidity. No technique has gained widespread popularity, as each technique has its advantage and drawbacks. The Koyanagi technique combines the release of chordee and construction of urethra using two meatal-based flaps into a single procedure. Many modifications applied to this technique aiming to improve the blood supply of the neourethral flaps to achieve good healing for minimizing postoperative complications ${ }^{(4,5)}$.

Therefore, the purpose of this study was to evaluate the outcome of Koyanagi technique modification using dartos muscle as a $2^{\text {nd }}$ layer because it is a highly vascular tissue, very thin, easily elevated, and leaves no complications.

\section{PATIENT AND METHODS}

This study was conducted in the Plastic Surgery Department at Menoufia University, within the period of April 2017 to April 2019. Thirty cases of proximal hypospadias were included in this study. The singlephase repair, modified Koyanagi technique by using scrotal dartos muscle flap as a $2^{\text {nd }}$ layer was performed for all of them.

\section{Ethical considerations:}

All procedures were carried out according to the ethical standards of the institutional committee and with the 1964 Declaration of Helsinki. The study received the contest of Ethical Committee of Faculty Medicine, Menoufia University. The aim and steps of the study were explained to the parents and written au courant consent were acquired from them.

Inclusion criteria: Children with proximal hypospadias, presence of chordee, intact prepuce and healthy penile skin.

Exclusion criteria: Children with anterior hypospadias, previously operated using preputial flap and circumcised patients or severely scared penile skin.

\section{Methods}

Patient Preparation: All patients were subjected to thorough clinical evaluation, routine laboratory investigations, and abdominopelvic ultrasonography to exclude other associated anomalies. All patients, after complete release of chordee, had modified Koyanagi technique. All operations were completely performed 
by the authors, using fine instruments and interrupted sutures under $3.5 \mathrm{X}$ loupe magnification to perform gentle tissue handling.

Patients were operated under general anesthesia and third generation cephalosporin as a prophylaxis. A skin-incision line was drawn using marking pen (Fig. 1a). Hanging suture was done using proline $2 / 0$ just dorsal to the tip of glans for straightening the penis and to facilitate incisions and dissection through the procedure. Nelaton catheter (6 or $8 \mathrm{~F}$ ) was placed (Fig. 1b). Circumferential incision $5 \mathrm{~mm}$ proximal to the corona was done extending to the ventral aspect of the penis distal to the urethral opening. The urethral plate was incised for chordee release (Fig. 1c).

After complete releasing the chordee, the inner edge of the neourethra forming flaps was performed that was reaching the Bucks fascia (Fig. 1d). A Ushaped skin incision was then made surrounding the meatus proximally, to extend the skin along the marked line. This lateral incision was extended into the prepuce, $8 \mathrm{~mm}$ parallel to the first incision. This incision was done only through the skin preserving the dartos fascia that carries the vascularity to the neourethra flaps (Fig. 1e).

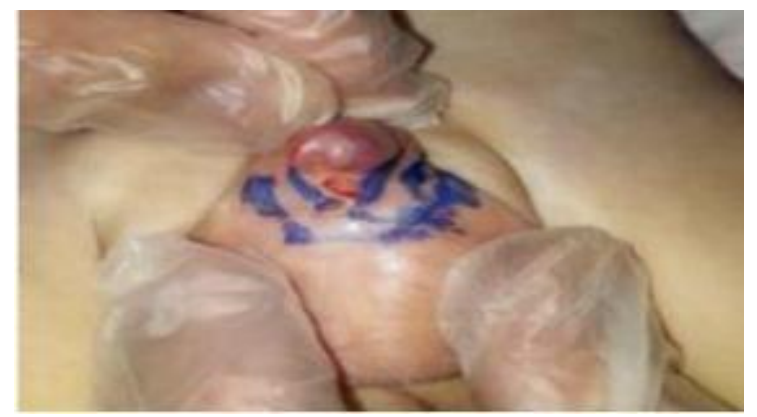

Fig 1a

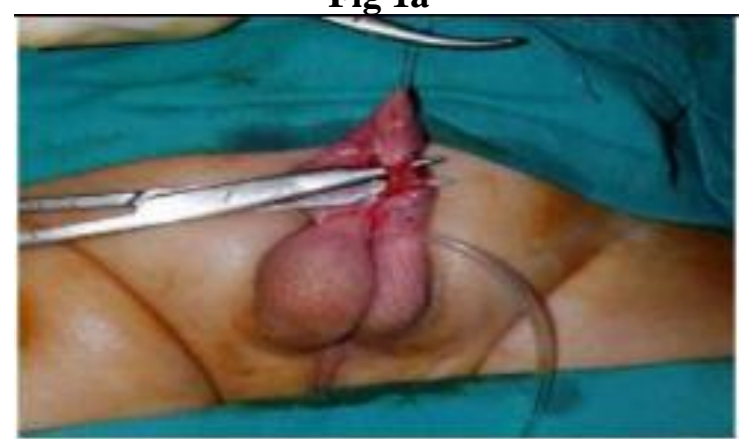

Fig 1c

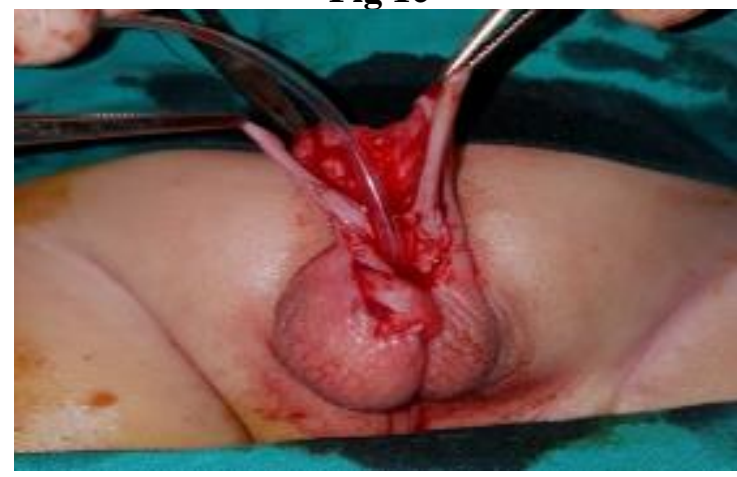

Fig 1e
This V-shaped two skin flaps were sutured in two lines to create a new urethra (Fig. 1f). The distal urethral meatus place was created by splitting the glans vertically. Bilateral sharp dissection was done to allow the creation of two wings (Fig. 1 g).

The internal sides of the flaps were sutured with each other with interrupted dermal bites using 6/0 polyglactin sutures (Fig. 1h). The external sides were sutured, over the catheter, as minutely as possible in an interrupted subcuticular manner with the same sutures (Fig. 1i). The neourethra was placed within the groove in the glans and anastomosed with the tip (Fig. 1j). Vertical incision over the scrotal raphe was done to dissect dartos muscle flap. It was mobilized proximally based and fixed to covering the neourethra suture line using polyglactin 6/0 simple sutures (Fig. 1 k, L). The glans wings were sutured through the distal portion of the neourethra by vertical mattress polyglactin 5/0 sutures. Skin coverage was done using the dorsal foreskin, turned towards the ventral side and sutured to cover the ventral skin defect (Fig. 1m). The catheter was fixed using the traction suture and left there for 7 days. Follow up was continued for 3 to 12 months. Results and complications were recorded.

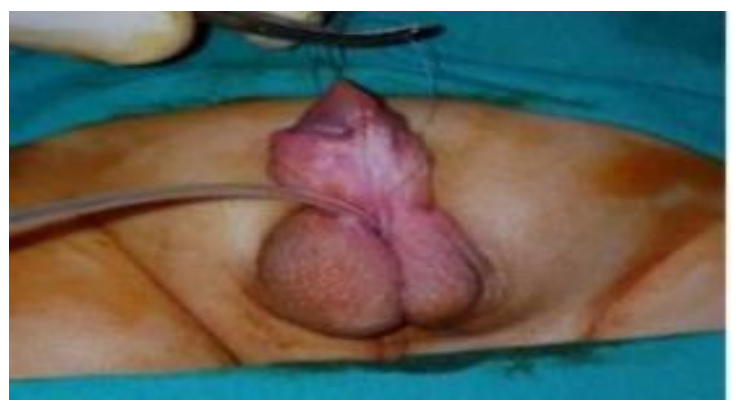

Fig 1b

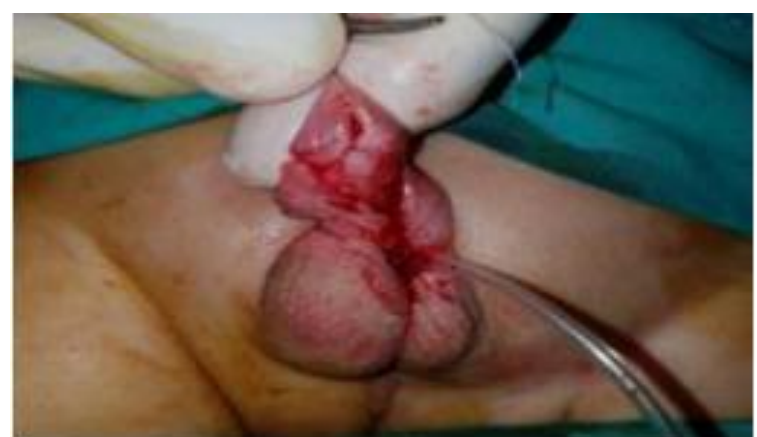

Fig 1d

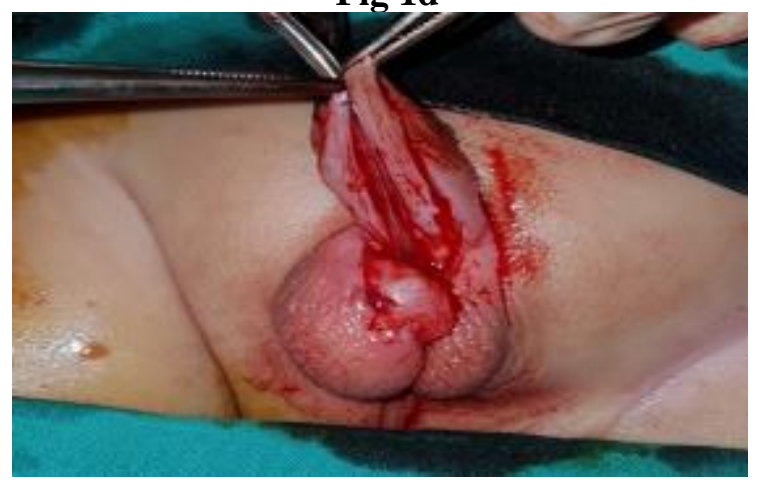

Fig 1f 


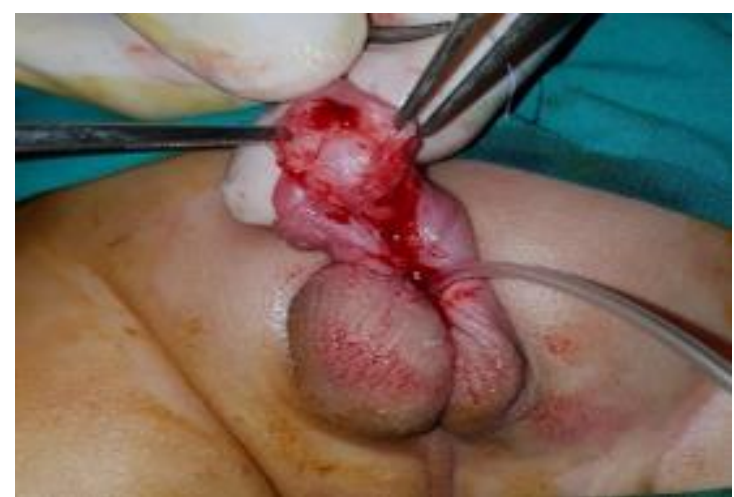

Fig 19

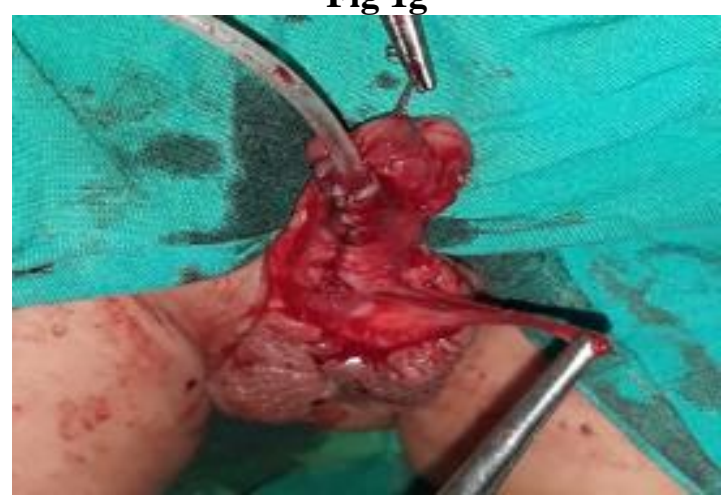

Fig 1i

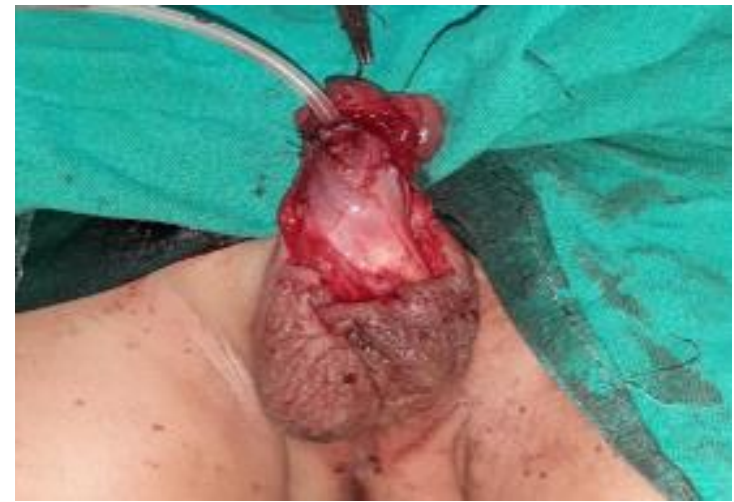

Fig 1k

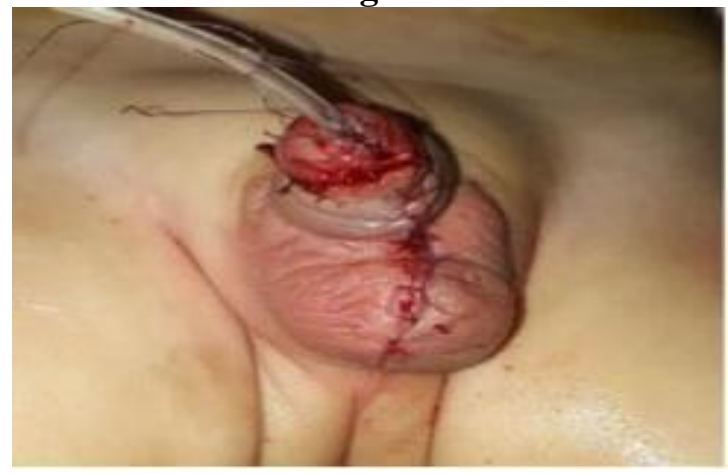

Fig 1m

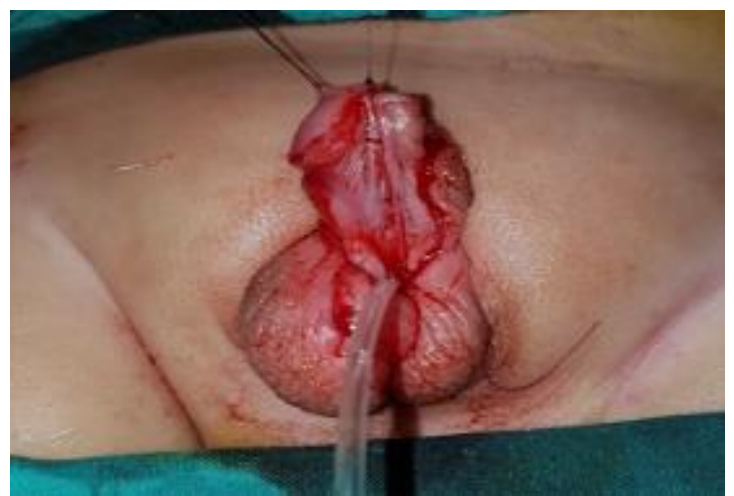

Fig 1h

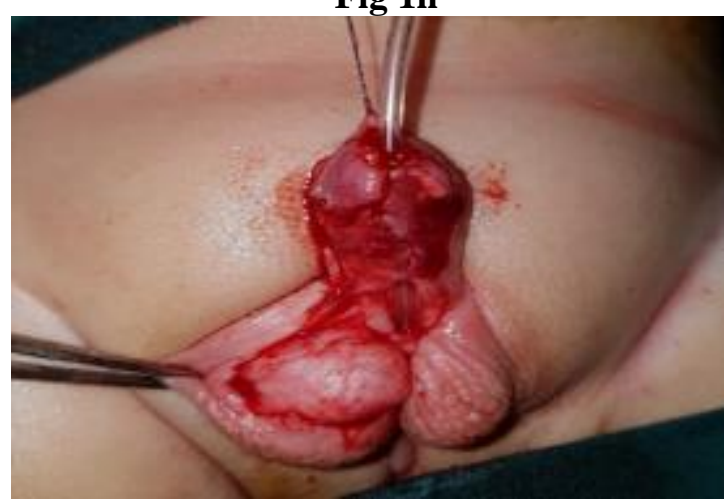

Fig 1j

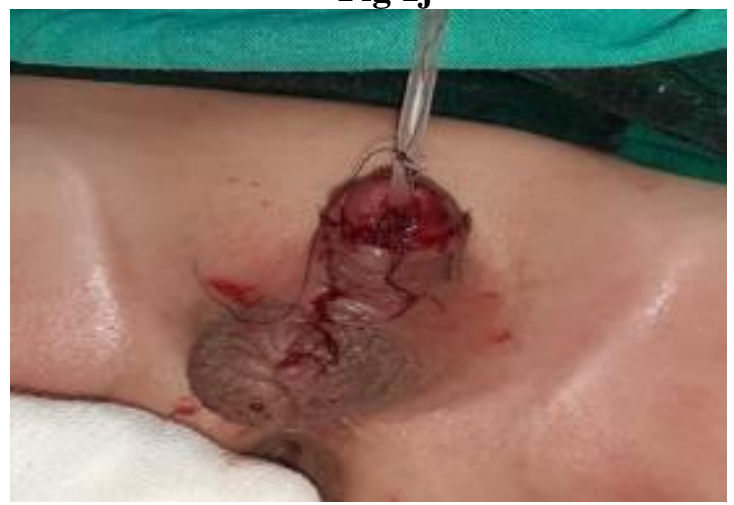

Fig 11

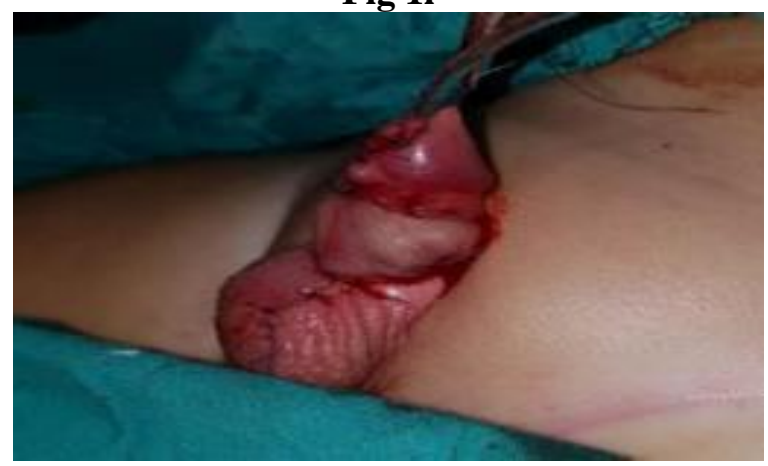

Fig 1n

Figure (1): Steps of the operation using modified Koyanagi technique using dartos muscle flap in management of proximal hypospadias. 


\section{Statistical analysis}

Results were arranged and statistically analyzed by using Microsoft excel 2019 and SPSS v.25 program for Microsoft windows 10. The description of data were in the form of mean $( \pm)$ SD and range for quantitative data, and frequency and proportion for qualitative data. Chi-Square $\left(\chi^{2}\right)$ was used to compare qualitative data. $\mathrm{P}<0.05$ was considered a significant level.

\section{RESULTS}

Our results showed that, patient's age ranged from 1 to 4 years with mean age of $2.83 \pm 1.17$. There was significant differences as regard type of hypospadias and associated anomaly (Table 1).

Table (1): Type of hypospadias and associated anomaly among the studied male patients.

\begin{tabular}{|l|c|c|}
\hline & \multicolumn{2}{|c|}{$\begin{array}{c}\text { The studied } \\
\text { patients } \\
\text { (N=30) }\end{array}$} \\
\hline Type of hypospadias & No. & \% \\
\hline Proximal penile hypospadias & 9 & 30 \\
\hline Penoscrotal hypospadias & 15 & 50 \\
\hline Scrotal hypospadias & 5 & 16.67 \\
\hline Perineal type & 1 & 3.33 \\
\hline \multicolumn{1}{|c|}{ P value } & $0.003 *$ \\
\hline Associated anomaly & No. & \% \\
\hline $\begin{array}{l}\text { Free from associated local } \\
\text { anomaly }\end{array}$ & 21 & 70 \\
\hline Associated local anomaly & 9 & 30 \\
\hline Unilateral undescended testicle & 3 & 10 \\
\hline \multicolumn{3}{|c|}{0.043} \\
\hline Type of associated anomaly (N= 6) \\
\hline $\begin{array}{l}\text { Bilateral undescended testicle } \\
\text { Unilateral congenital inguinal } \\
\text { hernia }\end{array}$ & 2 & 6.67 \\
$\begin{array}{l}\text { One side undescended testicle } \\
\text { and the other side oblique } \\
\text { inguinal hernia }\end{array}$ & 2 & 6.67 \\
\hline \multicolumn{2}{|c|}{ P value } & 6.67 \\
\hline
\end{tabular}

Regarding, Consanguinity was positive in 6 patients (20\%) while the rest 24 patients $(80 \%)$ were negative. Drug intake by the mother found in 12 case (40\%) as the drugs that enhance pregnancy or to fix the threatened abortion or any other medical conditions while the remaining 18 patients $(60 \%)$ were negative drug intake. for increase penis size in micro phallus, topical androgen was used prior to surgery for a period of two months with mild to moderate results,

(Table 2).
Table (2): Incidence of drug usage during pregnancy, consanguinity and percentage of patients using androgen prior to surgery in the studied patients.

\begin{tabular}{|l|c|c|}
\hline \multirow{2}{*}{} & \multicolumn{2}{|c|}{$\begin{array}{c}\text { The studied } \\
\text { patients } \mathbf{N = 3 0}\end{array}$} \\
\cline { 2 - 3 } & No. & \% \\
\hline $\begin{array}{l}\text { Consanguinity } \\
\text { Positive } \\
\text { Negative }\end{array}$ & 6 & 20.00 \\
\hline $\begin{array}{l}\text { Drug intake by the mother } \\
\text { Positive }\end{array}$ & 18 & 80.00 \\
$\begin{array}{l}\text { Negative } \\
\text { (enhance pregnancy or to fix } \\
\text { the threatened abortion or } \\
\text { any other medical } \\
\text { conditions) }\end{array}$ & 12 & 40.00 \\
\hline $\begin{array}{l}\text { Androgen prior to surgery } \\
\text { Yes } \\
\text { No }\end{array}$ & 18 & 60.00 \\
\hline \multicolumn{1}{|c|}{ of } & $2.12 \pm 0.75$ & $1-3$ \\
\hline $\begin{array}{l}\text { Duration } \\
\text { androgen/month }\end{array}$ & Mean \\
\hline
\end{tabular}

Through the period of follow up, early complications were detected as bleeding in 2 patients $(6.6 \%)$. One patient $(3.3 \%)$ reported for retention due to obstruction of the inserted catheter that's failed to be cleared, supra pubic cysto catheter was inserted and kept for three weeks but after removal of the catheter the patient developed penoscrotal fistula. Infection in the suture line was reported in one patient (3.3\%), that's managed by local and systemic antibiotics, repeated dressings, this patient later developed recession of meatus,. In our results, the reported late complications during postoperative follow up were the fistula, meatal recession, meatal stenosis, and diverticulum.

Fistula was reported in six patients $(20 \%)$ that's needs a second operations 6 months later. Meatal recession was reported in 5 patients $(16.6 \%)$. Two parents were satisfied with the results and three were corrected by urethral advancement. Urethral diverticulum was reported in one patient $(3.3 \%)$ diagnosed by dysuria and ascending urethrogram. Second stage repair was planned for complicated patients after six months. Stenosis was reported in three patients $(10 \%)$, to which tip dilatations were done successful, (Table 3). 
Table (3): Early complications and late complications among the studied males' patients.

\begin{tabular}{|c|c|c|c|c|}
\hline \multirow{3}{*}{ 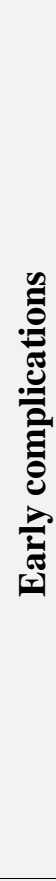 } & & No & $\%$ & Managing \\
\hline & $\begin{array}{l}\text { Immediate } \\
\text { bleeding }\end{array}$ & 3 & 10.0 & $\begin{array}{l}\text { Conservatively managed } \\
\text { in } 2 \text { patients }(6.6 \%) \text {. One } \\
\text { patient }(3.3 \%) \text { reported } \\
\text { for retention due to } \\
\text { obstruction of the } \\
\text { inserted catheter that's } \\
\text { failed to be cleared, } \\
\text { suprapubic cysto } \\
\text { catheter was inserted and } \\
\text { kept for one week but } \\
\text { after removal of the } \\
\text { catheter the patient } \\
\text { developed penoscrotal } \\
\text { fistula. }\end{array}$ \\
\hline & $\begin{array}{l}\text { Infection in } \\
\text { the suture } \\
\text { line }\end{array}$ & 1 & 3.33 & $\begin{array}{l}\text { Local and systemic } \\
\text { antibiotics, repeated } \\
\text { dressings, wound swab } \\
\text { was done for culture and } \\
\text { sensitivity. }\end{array}$ \\
\hline \multirow{5}{*}{ 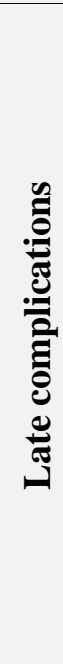 } & Fistl & 6 & 20.0 & $\begin{array}{l}\text { Penoscrotal site that's } \\
\text { needs second operations } \\
6 \text { months later }\end{array}$ \\
\hline & $\begin{array}{l}\text { Meatal } \\
\text { recession }\end{array}$ & 5 & 16.67 & $\begin{array}{l}\text { Two parents were } \\
\text { satisfied with the results } \\
\text { and three were corrected } \\
\text { by urethral advancement }\end{array}$ \\
\hline & Glan & 1 & 3.33 & \\
\hline & $\begin{array}{l}\text { Urethral } \\
\text { diverticulum }\end{array}$ & 1 & 3.33 & $\begin{array}{l}\text { Second stage repair was } \\
\text { planned for complicated } \\
\text { patients after six months }\end{array}$ \\
\hline & Stenosis & 3 & 10.0 & $\begin{array}{l}\text { To which three sessions } \\
\text { of dilatations were done } \\
\text { each }\end{array}$ \\
\hline
\end{tabular}

After 6 months, 9 patients (30\%) needed redo surgeries. Five cases to repair fistula. Two cases to advance the recessed meatus), one patient for the recession of meatus and fistula and another for the diverticulum correction (Table 4).

Table (4): Cases needed redo surgeries in the studied patients

\begin{tabular}{|l|c|c|}
\hline \multirow{2}{*}{ Needed redo surgeries for } & \multicolumn{2}{|c|}{ The studied patients } \\
\cline { 2 - 3 } & $\begin{array}{c}\text { No } \\
(\mathbf{n = 1 0})\end{array}$ & $\begin{array}{c}\mathbf{\%} \\
\mathbf{( 3 3 . 3 0 \% )}\end{array}$ \\
\hline Recession of meatus & 2 & 20.0 \\
\hline The fistula & 5 & 50.0 \\
\hline Glandular torsion & 1 & 10.0 \\
\hline Recession of meatus and fistula & 1 & 10.0 \\
\hline The diverticulum & 1 & 10.0 \\
\hline \multicolumn{2}{|c|}{ P value } & \multicolumn{2}{|c|}{0.199} \\
\hline
\end{tabular}

\section{DISCUSSION}

Among all degrees of hypospadias, proximal hypospadias represents the rarest but the most challenging and complex hypospadias degrees and could be managed by different techniques that vary between single or two or even more stages repair ${ }^{\left({ }^{(6)}\right.}$. There was no one technique has gained widespread popularity. Whether two stage or one-stage, each technique has its benefits and drawbacks. Mastering one technique as the gold standard for posterior hypospadias is probably unrealistic. So, the surgeon must master different techniques because patients vary in their specifics that's favor one or another technique. Many variables may interfere for a chosen technique as site of meatus, availability of surrounding tissue, presence of other anomaly, bifid scrotum, previous operations or the condition after release of the chordee. Proximal hypospadias is usually associated with reasonable chordee that needs complete release to straight the penis before urethral construction. This makes concomitant reconstruction using local tissue is far accepted. So, we may postpone urethral reconstruction to a second stage ${ }^{(7)}$.

Some one stage techniques were reported using preputial flap to reconstruct the urethra, but the site of the anastomosis between the neourethra and the presented meatus is commonly liable to fistula. Scrotal median raphe flap was used to reconstruct a neourethra which has a high vascularity but usually result in penile ventral pending. Koyanagi et al. ${ }^{\left({ }^{(8)}\right.}$ developed two long parameatal based flaps from the urethral orifice extending through all the penile shaft till the prepuce, which is a procedure called "wing flapflipping urethroplasty". The two flaps then transferred ventrally to be tabularized allowing one stage correction.

This technique provides enough skin for the neourethra, as the range from the meatus to the dorsal preputial midline is always longer than the mileage of the meatus to the tip of the glans. Other advantages that are the chordee can be released in the same stage, and neither bulking nor torsion of the penile shaft are noticed as resulted in some other techniques. The parameatal tissues use abolishes the need for a circumferential anastomosis between the hypostatic meatus and neourethra as in preputial flap ${ }^{(9)}$.

Although Koyanagi technique appeared to supply a perfect resolution for proximal hypospadias, the reported Koyanagi experience was discouraging because of high complication particularly the appearance of fistulae and reoperation average. In the largest and most recent series by Koyanagi et al. ${ }^{(10)}$ of 70 patients, the complications rate requiring a second operation was $47 \%$. It included fistula in $21 \%$ and meatal stenosis in $26 \%$ of the cases. Glassberg $\boldsymbol{e t}$ al. (11) did a study on Koyanagi technique in a recent series of patients and the required secondary operation was for $50 \%$ of cases. 
Complication rates ranged between 20 to $50 \%$. This apparently high number must be put into perspective in that if a staged repair is done, $100 \%$ of patients will undergo at least two operations with a probability of requiring a third or more for complications that's could occur after urethral tabularization. However, a large number of patients underwent Koyanagi repair may request a second technique, numerous of the patients only require one operation. Consequently, by using this approach, patients with proximal hypospadias may require stages much less than if a planned two-stage approach is used (12).

As it is a one phase operation, a main advantage of Koyanagi technique is that all main anatomy is performed in untouched, virgin tissue allowing neourethral reconstruction without any scar tissue affecting vascularity. It has the added advantage that a lower dissection is required so flaps vascularity is preserved. This technique also permits simultaneous reform of related penoscrotal transposition or bifid scrotum, if present. Gil Rushton ${ }^{(13)}$ also mentioned that the high complexity range associated with the Koyanagi repair was probably caused by failure to preserve the axial blood supply to the long parameatal ventral preputial skin flaps applied to construct the neourethra. Emir et al. ${ }^{(14)}$ advocated that defeat to maintain adequate blood supply to the flaps may result in ischemia with decreased tissue viability that in hypospadias reform typically manifests as a fistula or urethral stricture. In the presented work we overcome these problems by avoiding much dissection to the flaps and to do urethral construction using interrupted $6 / 0$ absorbable sutures. Many modifications to this procedure have been made trying to improve the blood supply and to minimize the complications.

Snow and Cartwright (15) modified the Koyanagi technique by using an island-flap procedure to preserve a reliable binary blood supply for the long neourethra. As they deglove the whole penile skin along Buck's fascia, but preserve the blood supply to the neourethral flap by limiting the outer incision depth to be only through skin and dermis. Glans penis is drawn through buttonhole in the vascular pedicle, transposing the entire urethra and vascular pedicle to the ventral aspect of the penis. Their four cases only series resulted in 50\% success rate. All the complicated cases $(50 \%)$ presented with urethrocutaneous fistula. They didn't report any additional results with their modification ${ }^{(9)}$.

In 2001, Sugita et al. ${ }^{(16)}$ modified the Koyanagi technique by removing the subcutaneous tissue of the distal section of the flap during the prepuce that covered by the glans. They believed that the blood supply is not reliable at the distal part of the flap and it is better to be dealt with as a free graft rather than a vascularized flap. A success rate of $83 \%$ was achieved on their study of 151 patients. Complications were stenosis (2\%) and fistula (13\%). In 2016, Kang et al. (6) operated on a series of 24 patients using Koyanagi technique preserving all the dartos fascia as a blood supply. They observed 3 cases of urethral fistula and urethral dehiscence in the prior 7 cases. Later they used the tunica vaginalis (in 12 patients) or scrotal dartos (in 5 patients) as a second layer with only one patient complicated with fistula.

In the present study, we tried to preserve vascularity to the constructing flaps to minimize complications. Gentleness in handling tissue is important with meticulous instruments, good light and loop magnification. Lateral incisions of the flaps affect skin only with preservation the dartos fascia and minimal dissection of the flap to be sutured in the midline. 6/0 polyglycolic acid sutures were utilized with interrupted (not continuous) technique not to affect vascularity of the edge and to suture only the dermis taking care not to penetrate the epidermis. Glans incision was done deep creating two lateral wings to accommodate terminal part of the neourethra and subject a good vascularity for sound healing. Dartos muscle flap with its high vascularity was added to cover the reconstructed urethra to enhance healing and separate its sutures from skin covering sutures minimizing probability of fistula occurrence. The results were encouraging, and range of complications were accepted.

In the present study 30 cases were dealt with using the presented technique with $60 \%$ success rate. Next a reasonable period of follow up (3 to 12 months), there were 6 cases with fistula, 5 with meatal recession, and another one with urethral diverticulum. Association of external genitalia anomalies seems not to affect the results in this technique if not affecting the vascularity of the used tissue. In the presented study there were 9 patients (30\%) who had other local anomalies and the percentage of success was similar to that free of associated anomalies. Mouriquand and Mure ${ }^{(17)}$ published their study in 2009 with a success rate of $39 \%$, they had a series of 31 patients, $16 \%$ had associated external genitalia anomaly and almost $80 \%$ of them received preoperative hormonal therapy. They reported complications of meatal stenosis (16\%), urethral-cutaneous fistula (39\%), meatal recession (19\%), and diverticulum (9\%). Nerli et al. (18) published their study in 2010, they worked on sample sized 14 patients, their age ranged from 3 to 9 years old. $28 \%$ of the patients had associated external genitalia anomaly. Their success rate was $64 \%$, with reported complications of fistula in $21 \%$, meatal recession of $7 \%$ and diverticulum in 7\%. Elkassaby $\boldsymbol{e t}$ al. ${ }^{(19)}$ published their study in 2013, it was done on sample sized 20 patients, and $25 \%$ of them had an associated external genitalia anomaly. They had $60 \%$ success rate. They reported bleeding in 5\% and infection in $20 \%$ as early complications and stenosis in 
$5 \%$, fistula in $40 \%$, meatal recession $10 \%$ and torsion in $5 \%$ of the cases as late complications.

In our study, local testosterone was used preoperatively. It seems to increase the penile size and make manipulation of tissue easier. Elsaied et al. ${ }^{(5)}$ published their study in 2010, it was done on 30 patients, and $30 \%$ of them received preoperative hormonal therapy. In their study, they achieved $90 \%$ success rate. Fistula in 7\% and meatal recession in 3\% of cases was reported. Vepakomma et al. (20) published their study in 2013 with 54\% success rate, it was done on sample sized 24 patients. Stenosis in $12 \%$, fistula in $21 \%$, meatal recession in $8 \%$ and torsion in $4 \%$ of cases were reported. Elhalaby et al. (21) published their study in 2006 with a success rate of $82 \%$. They operated upon 11 patients, all of them received preoperative hormonal therapy. They detected fistula in $18 \%$, meatal recession in $9 \%$, and diverticulum in $9 \%$ of the cases. Abdalaleem et al. ${ }^{(22)}$ published their study in 2016 with 55\% success rate, it was done on sample sized 20 patients. $30 \%$ of the patients had an associated external genitalia anomaly. Preoperative hormonal therapy applied for $60 \%$ of the cases. They reported bleeding in 5\%, infection in 5\% and urine retention in $5 \%$ as early complications and stenosis in $15 \%$, fistula in $20 \%$, meatal recession in $25 \%$, torsion in $5 \%$ and diverticulum in $5 \%$ of cases as late complications.

\section{CONCLUSION}

The modified Koyanagi is one phase repair of proximal hypospadias. It is an innovative procedure that fulfills many criteria for predictable successful operative results. Great care should be given to meticulous dissection and delicate instruments. It is also believed that the use of dartos muscle flap wrap as a cover for the urethroplasty improves the results.

\section{REFERENCES}

1. Stein $\mathbf{R}$ (2012): Hypospadias. European Urology Supplements, 11(2):33-45.

2. Alexander K, Leung W (2007): Hypospadias: an update. Asian J Androl., 9:16-22.

3. Steven L, Cherian A, Yankovic F et al. (2013): Current practice in paediatric hypospadias surgery; a specialist survey. Journal of Pediatric Urology, 9(6): 1126-30.

4. Arnaud A, Harper L, Aulagne M et al. (2011): Choosing a technique for severe hypospadias. African Journal of Paediatric Surgery, 8(3):286-92.

5. Elsaied A, Saied B, El-Ghazaly M (2010): Modified Koyanagi technique in management of proximal hypospadias. Annals of Pediatric Surgery, 6(1):22-6.

6. Kang L, Huang G, Zeng L et al. (2016): New modification of the Koyanagi procedure for the one-stage repair of severe hypospadias. Urology, 93:175-9.
7. Hayashi Y, Kojima Y, Mizuno K et al. (2001): The modified Koyanagi repair for much proximal hypospadias. BJU International, 87(3):235-8.

8. Koyanagi T, Matsuno T, Nonomura K et al. (1983): Complete repair of severe penoscrotal hypospadias in 1 stage: experience with urethral mobilization, wing flapflipping urethroplasty and "glanulomeatoplasty". The Journal of Urology, 130(6):1150-3.

9. Hayashi Y, Kojima Y, Mizuno K et al. (2007): Neomodified Koyanagi technique for the single-stage repair of proximal hypospadias. Journal of Pediatric Urology, 3(3):239-42.

10. Koyanagi T, Nonomura K, Kakizaki H et al. (1993): Experience with one-stage repair of severe proximal hypospadias: operative technique and results. Eur Urol., 24: 106-110.

11. Glassberg K, Hansbrough F, Horowitz M (1998): The KoyanagiNonomura 1- stage bucket repair of severe hypospadias with and without penoscrotal transposition. $\mathbf{J}$ Urol., 160:1104.

12. Jayanthi V (2008): The modified Koyanagi hypospadias repair for the one-stage repair of proximal hypospadias. Indian journal of urology: IJU: journal of the Urological Society of India, 24(2):206-11.

13. Gil Rushton H (1994): Hypospadias. The Journal of Urology, 152(4):1241-2.

14. Emir H, Jayanthi V, Nitahara $K$ et al. (2000): Modification of the Koyanagi technique for the single stage repair of proximal hypospadias. The Journal of Urology, 164(3):973-6.

15. Snow B, Cartwright P (1994): Yoke hypospadias repair. J Pediatr Surg., 29: 557:60.

16. Sugita Y, Tanikaze S, Yoshino K et al. (2001): Severe hypospadias repair with meatal based paracoronal skin flap: the modified Koyanagi repair. The Journal of Urology, 166(3):1051-3.

17. Mouriquand P, Mure $\mathbf{P}$ (2004): Current concepts in hypospadiology. BJU International, 93:26-34.

18. Nerli R, Santhoshi P, Guntaka A et al. (2010): Modified Koyanagi's procedure for proximal hypospadias: our experience. International Journal of Urology, 17(3):294-6.

19. Elkassaby M, Shahin M, El-Sayaad I et al. (2013): Comparative study between modified Koyanagi and Snodgrass techniques in management of proximal types of hypospadias. Journal of Taibah University Medical Sciences, 8(2):97-104.

20. Vepakomma D, Alladi A, Ramareddy R et al. (2013): Modified koyanagi repair for severe hypospadias. Journal of Indian Association of Pediatric Surgeons, 18(3):96-103.

21. Elhalaby E (2006): One-Stage Repair of Severe Hypospadias: Original versus Modified Koyanagi. Annals of Pediatric Surgery, 2(1):32-8.

22. Abdalaleem A, Tagy G, Kaddah S et al. (2016): Modified koyanagi technique for the single---stage repair of proximal hypospadias", 5th World Congress of Pediatric Surgery, Washington DC, World Federation of Associations of $\begin{array}{lll}\text { Pediatric } & \text { Surgeons, } & \text { Pp. }\end{array}$ https://www.researchgate.net/publication/322725926_modi fied_koyanagi_technique_for_the_single--stage_repair_of_proximal_hypospadias. 